\title{
Preparing for the inevitable
}

$\mathrm{T}$ he human body is not made to last. Sure, some bodies are heartier than others. Some last for more than a century - not many, but a few. Others are far less fortunate, born with disease or genetic defect, their final breaths occurring not long after their first. Some bodies expire suddenly, victims of fires, head-on collisions, massive heart attacks or any number of other calamities that steal life without warning.

But the bodies of those fortunate enough to live lives free of premature catastrophe, be it internal or external, follow a more predictable journey. They start out weak and helpless, grow stronger over the course of three decades or so, and then begin a long, slow decline that accelerates near the end of life and culminates, always, in death. Advances in medicine and health education have extended this journey, but no matter how long the road, the mileposts remain the same.

The start of this journey is always cause for celebration. The long middle is filled with work and hobbies and the raising of children. The last part of the journey is something that people, in general, don't like to think about. That's unfortunate, according to those who provide care for people during their final years, because ignoring the inevitable only makes the inevitable worse.

"An unplanned death is a poorquality death," says Dr. Daren Heyland, a professor of medicine and epidemiology at Queen's University in Kingston, Ontario, who recently published a survey of Canadians' opinions on priority areas for improving end-of-life care (www.cmaj.ca/cgi/doi/10.1503 /cmaj.100131).

It isn't just death, however, that many people fail to plan for. When they begin to lose their independence, people start down a long and complex path of care, the details of which few people make an effort to understand. Experts in the "care years" say that

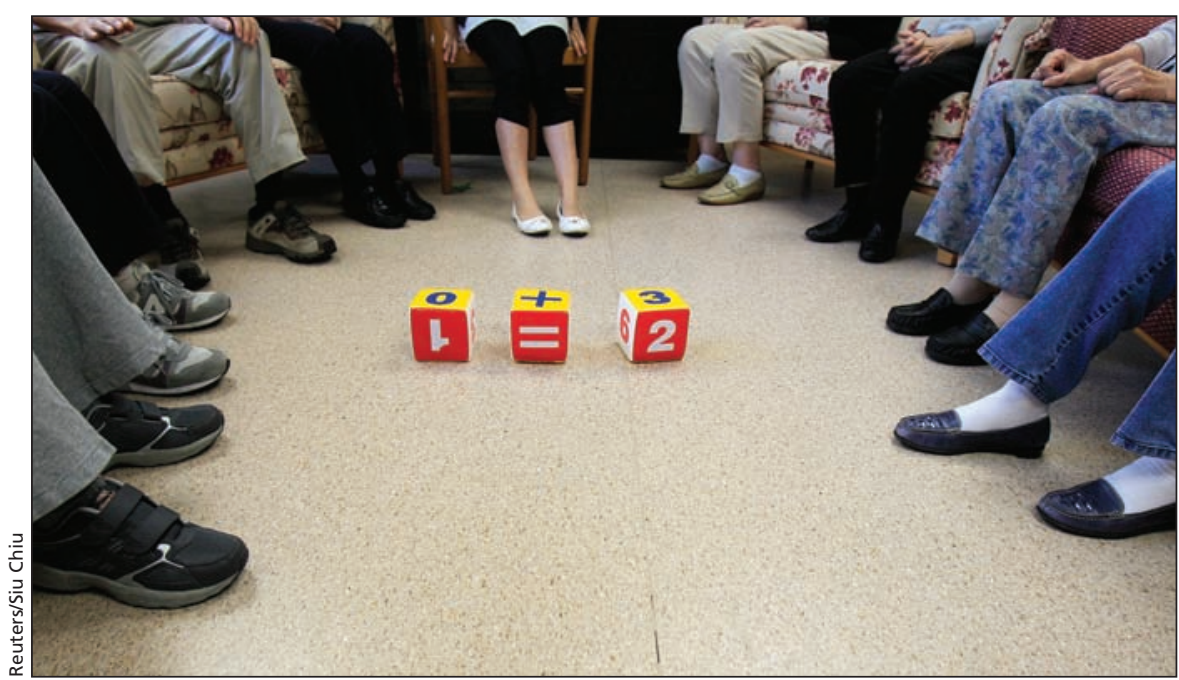

People with Alzheimer disease attend memory training at a community clinic.

people who need care, and their families, must educate themselves on what services their provinces offer. Then they should make decisions on where that care will occur, who will manage it and how it will be financed.

But the responsibility for improving people's care years doesn't fall only on families. Some doctors are beginning to question their profession's approach to caring for people during their final years, which often consists, at least near the end, of aggressive medical interventions that prolong life only for short periods. According to Heyland, physicians must become more aware that the greatest pain people experience at the end of their lives is not always physical, but rather may be emotional or spiritual, and it is important that efforts be made to reduce these types of pain as well.

"We, as physicians, have a responsibility to do it ourselves or to reach out and get other members of our teams to do it," he says.

Patty Randall, author of the 2007 book Let's Talk - The Care-Years: Taking Care of Our Parents/Planning for Ourselves, calls the path of care people follow as they lose their independence the "care-years continuum." It consists of: family care/management; government home care/nursing services; assisted-living care; part-time, athome care; live-in, 24-hour care; nursing home care; and extended hospital/palliative care. As people move along the continuum, their needs increase, as does the intensity of care they require.

"The care continuum is not understood in Canada," says Randall. "Canadians are a bit mystified by it."

One reason why Canadians know so little about it, says Randall, is their sense of entitlement. Canadians appear to believe the health care system will take care of them and so they needn't be overly concerned about the details of the care they will eventually require. Not so, says Randall. Governments will provide some funding and services, but the bulk of the responsibility falls to families for managing the care of people who can no longer fully care for themselves. Without proper planning, managing care for ailing parents can have devastating effects on people's physical and financial well-being.

"The 'black death' of your financial plan," says Randall, "are your parents."

Like other experts in this area, Randall, who gained her expertise by managing her own parents' end-of-life care, says that education is key. A federal government-run national campaign - 
consisting of television, radio and other types of media - targeted at baby boomers with aging parents would be a good start, she says. People simply need information, and there is no good place right now where they can find it.

The need for education about careyears planning is more important today than ever before, says Randall, because unlike in generations past, people can now expect to live for up to 30 years after retirement. "That is a third of your life for which there is no precedent, and part of that will be spent in care. Still, people spend more time planning for a big holiday than for their care years."

The early part of people's care years are typically spent at home. Provincial governments offer home care services, all providing a few basic services, such as nursing and case management. But many services - including speech therapy, housekeeping, respiratory therapy, social work and dietetics - are funded in some provinces but not in others. One reason why the provinces have many different versions of home care is that Canada lacks a countrywide definition of home care.

"There should be a set of standards to define home care nationally," says Marg McAlister, project manager for the Canadian Home Care Association.

Most people who work in home care consider it to be as essential a part of the health care system as hospital care, and would like to see the creation of a national home care program, says Margaret MacAdam, president of Age Advantage, a Toronto, Ontario-based company that offers gerontological consultation and strategic planning. "That would equalize what services would be covered," she says. "Or at least all provinces would offer a minimum basket of services."

When their health degrades to the point that living at home is no longer possible, people usually enter care facilities, such as nursing homes. Eventually, when health problems escalate to the point that death appears imminent, most people spend their final days in a hospital - sometimes in a palliative care unit, though most often in an acute-care bed.

In the arena of end-of-life care, Canada performs fairly well, though there is much room for improvement. According to an Economist Intelligence Unit ranking of the quality of end-of-life care provided by 40 countries, Canada comes in ninth, tied with the United States (www.eiu.com/site_info.asp?info _name $=$ qualityofdeath_lienfoundation \&page $=$ noads $\& \mathrm{rf}=0$ ).

The ranking is based on scores in four categories: basic end-of-life health care environment, availability of endof-life care, cost of end-of-life care and quality of end-of-life care. The United Kingdom, Australia and New Zealand top the list. Brazil, Uganda and India occupy the bottom three positions. The also extremely costly. As one US health consultant put it in the Economist Intelligence Unit's report: "We're the epicentre for the technologies that allow us to keep people alive for 60 additional days with no improvement in outcome but with substantial increases in cost."

In a recent essay called "Letting Go" in the New Yorker magazine, Dr. Atul Gawande, a writer and surgeon, describes the all-too-typical course of care for someone with a fatal illness (www.newyorker.com/reporting/2010 /08/02/100802fa_fact_gawande). The patient in his story is a 34-year-old

\section{"An unplanned death is a poor-quality death." — Dr. Daren Heyland}

primary reason that Canada doesn't rank higher is the burdensome cost to families of providing end-of-life care.

Even when palliative care is available and affordable, however, Canadians often don't take advantage of it, or at least not until the very end. "Most hospitals have palliative care programs but often don't get referrals until just a dozen days before death," says Sharon Baxter, executive director of the Canadian Hospice Palliative Care Association. "We would like to have the referrals much, much earlier."

According to the Economist Intelligence Unit's report, in some countries, such as China, palliative care is an afterthought because discussions of death are considered taboo. In western nations, accepting palliative care is associated with accepting defeat, which many aren't willing to do no matter how slim the odds of extending life. This is particularly true for younger people with fatal illnesses.

"People don't want to give up that hope that they are going to be cured," says Baxter.

As a result, health care systems in western countries have become oriented toward preventing death at all costs rather than helping people die without pain or mental distress. There's just one problem with making death an enemy: You always lose. And sometimes the fight is not only futile, but woman with inoperable cancer. She undergoes round after round of chemotherapy without improvement. When she has an allergic reaction to one type of medicine, she is given another. When that fails, her doctor recommends another drug that, on the slim chance it works, would extend her life by two months.

In the end, nothing works, and instead of spending the last months of her life in comfort, she spends them undergoing one aggressive treatment after another, even though none were likely to succeed. Experts in end-oflife care claim that when your final days are a blur of drugs and ventilators and defibrillators, it makes for a worse quality of life, a worse death and a worse experience for family members.

This is unlikely to change unless the culture of medicine itself changes, Gawande claims in his essay, because most all doctors are well-trained in how to keep a human heart beating, but many are ill-prepared to tell patients that it's time to give up the fight. "In the past few decades, medical science has rendered obsolete centuries of experience, tradition, and language about our mortality," writes Gawande, "and created a new difficulty for mankind: how to die." Roger Collier, CMAJ

CMAJ 2011.DOI:10.1503/cmaj.109-3704 